\title{
Enhanced Photocatalytic Performance of ZnO through Coupling with Carbon Materials
}

\author{
Kezhen Qi, ${ }^{*}$ Hanshu Qi, Yubo Xie, and Yan Wang* \\ Institute of Catalysis for Energy and Environment, College of Chemistry and Chemical Engineering, \\ Shenyang Normal University, Shenyang, Liaoning 110034, China
}

\begin{abstract}
Photocatalytic degradation of organic pollutants is an effective way to overcome environmental pollution. During the past few years, carbon materials have demonstrated great potential to improve photocatalytic performance of $\mathrm{ZnO}$ nanomaterials. This review will comment on recent developments of carbon materials (including fullerene, carbon nanotube, and graphene) coupling to improve photocatalytic performance of $\mathrm{ZnO}$ for photodegradatation of organic pollutants. The effects of carbon materials on enhancing photocatalytic performance of $\mathrm{ZnO}$ include enhancing structure stability, increasing amounts of active sites of pollutant adsorption, boosting electron acceptor formation and transport, enhancing photosensitization, narrowing band gap, etc. Moreover, basic mechanisms how carbon materials enhance photocatalytic activity of $\mathrm{ZnO}$ materials are discussed according to the interaction between $\mathrm{ZnO}$ and carbon materials. Finally, concluding remarks and current challenges are highlighted with perspectives for future developments of ZnO-based carbon photocatalysts. This review aims at recent research advances on $\mathrm{ZnO}$-based carbon photocatalysts developed for photocatalysis of organic contaminant degradation.
\end{abstract}

Keywords $\mathrm{ZnO}$, photocatalysis, carbon materials, coupling, organic pollutants

\section{Introduction}

With marching of industrialization, environmental pollution becomes more and more serious, especially organic pollutants in water. ${ }^{[1-3]}$ Various physical, chemical and biological treatments have been used to remove the organic pollutants. ${ }^{[4-6]}$ Since 1972, Fujishima and Honda ${ }^{[7]}$ observed the phenomenon of photoelectrochemical water splitting on semiconductor-based photocatalysts, the photocatalysis technology has been regarded as one of the promising ways to resolve organic pollutants. The basic requirement of photocatalysis is light absorption of photocatalysts. For instance, $\mathrm{ZnO},{ }^{[8-10]} \mathrm{TiO}_{2},{ }^{[11,12]}$ $\mathrm{CdS},{ }^{[13]} \mathrm{ZnS},{ }^{[14,15]} \mathrm{SrTiO}_{3},{ }^{[16]} \mathrm{BiOI}^{[17]}$ can be excited by light to excite electron $\left(\mathrm{e}^{-}\right)$in the conduction band and leave a hole $\left(\mathrm{h}^{+}\right)$in the valence band, which in turn triggers photoredox reaction.

Zinc oxide $(\mathrm{ZnO})$, as an important photocatalyst, has received much attention due to its excellent properties such as low cost, high redox potential, nontoxicity, and environmental friendness. ${ }^{[18-22]} \mathrm{ZnO}$ has wide band gap (3.37 eV) and large exciton binding energy (60 $\mathrm{meV}) .{ }^{[23]}$ Therefore, the main drawback that restricts its application is its fail to absorb visible light ( $43 \%$ of solar spectrum), only absorbing UV light ( $\sim \%$ of solar spectrum). ${ }^{[24]}$ The fast recombination of photogenerated electron-hole pairs also decreases the photocatalytic activity of $\mathrm{ZnO}$. During the past decades, great efforts have been devoted to improving $\mathrm{ZnO}$ to extend the response into visible-light domain and suppress the recombination of electron-hole pairs, ${ }^{[25-33]}$ such as doping metals or nonmetals, ${ }^{[34,35]}$ depositing noble metals, constructing heterojunctions ${ }^{[36]}$, etc. Recently, coupling carbon materials (for example, fullerene, carbon nanotube, graphene) with $\mathrm{ZnO}$ has been reported successfully for improving the photocatalytic performance of $\mathrm{ZnO} .^{[37-41]}$ However, until now, few reviews focus on
ZnO-based carbon photocatalysts. This paper affords recent developments on photocatalytic applications of $\mathrm{ZnO}$-based carbon composites. The carbon materials include fullerene $\left(\mathrm{C}_{60}\right)$, carbon nanotube, and graphene. The growing interests of $\mathrm{ZnO}$-based carbon composites are evidenced by increasing number of relevant publications from 2012 to 2016 (Figure 1). The statistics of publications reflect that carbon materials play an important role in the research area of nanoscience. This review aims particularly at recent research developments on $\mathrm{ZnO}$-based carbon composites to further develop effective photocatalysts for degradation of organic pollutants.

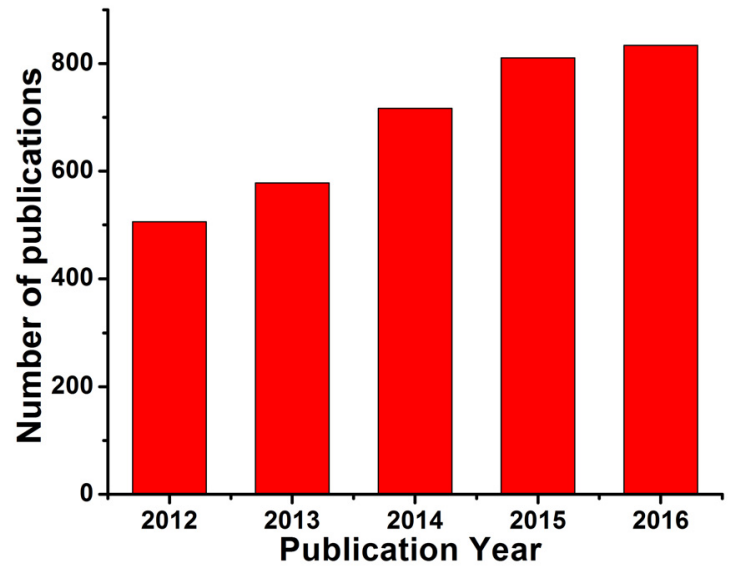

Figure 1 Statistics of papers published year by year relevant to $\mathrm{ZnO}$-based carbon composites. Data analysis is based on the Web of Science as of January 2017.

\footnotetext{
* E-mail: qkzh2003@aliyun.com, wangyan11287@mail.nankai.edu.cn Received December 22, 2016; accepted January 16, 2017.
} 


\section{Mechanisms of $\mathrm{ZnO}$ photocatalysis}

Figure 2 shows the mechanism of photocatalytic degradation of organic pollutants by $\mathrm{ZnO}$ nanoparticles. The photocatalytic process occurs when $\mathrm{ZnO}$ is irradiated by the light with the energy equal to or greater than the band gap energy of $\mathrm{ZnO}$. The absorption of light will cause charge carriers separation, and the excited electrons ( $\left.\mathrm{e}^{-}\right)$transfer from the valence band (VB) to the conduction band (CB), and the holes $\left(\mathrm{h}^{+}\right)$are left in the VB. ${ }^{[42]}$ Then, the charge-carriers $\left(\mathrm{e}^{-}\right.$and $\left.\mathrm{h}^{+}\right)$ will move to the surface of $\mathrm{ZnO}$ nanoparticles. However, this process is unavoidably along with the unwanted recombination of electrons and holes, which will reduce the quantum yield of the charge carriers. ${ }^{[43,44]}$ The active electrons and holes arriving at the $\mathrm{ZnO}$ surface will take part in reduction and oxidation reactions of common aqua solutions to produce hydroxyl radicals $(\mathrm{OH})$ and superoxide anion radicals $\left(\mathrm{O}_{2}^{-}\right)$, respectively. Finally, the highly reactive radical groups $\left({ }^{\circ} \mathrm{OH},{ }^{\circ} \mathrm{O}_{2}{ }^{-}\right)$will oxidize dye pollutant molecules contained in solution.

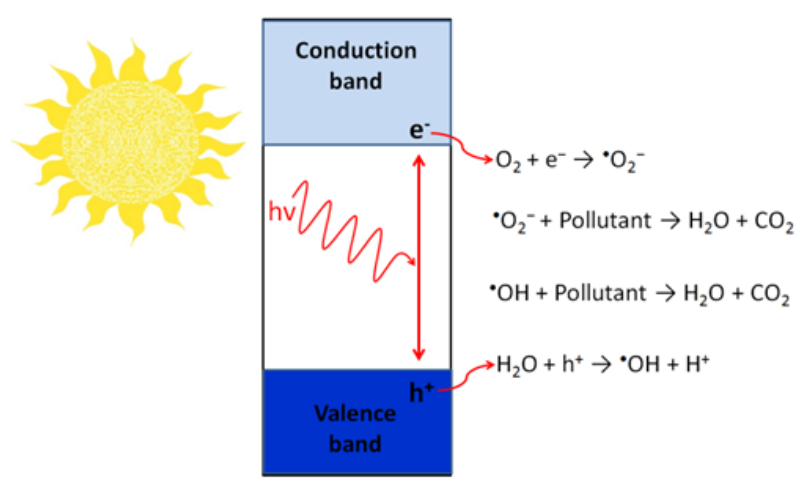

Figure 2 Basic mechanism of $\mathrm{ZnO}$ photocatalysis process.

\section{Coupling carbon materials}

The photocatalytic performance of $\mathrm{ZnO}$ can be improved by coupling with carbon materials such as fullerene, carbon tube and graphene (Figure 3), which can serve as a photoelectron reservoir to store and shuttle the photogenerated electrons from $\mathrm{ZnO}$ to substrates, or act as photosensitizer just like an organic dye. ${ }^{[45-50]}$
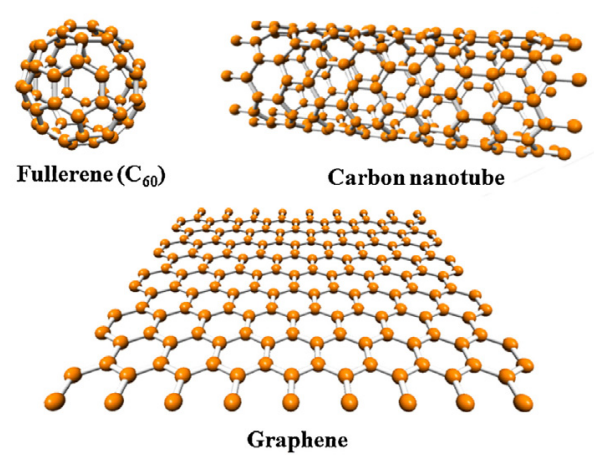

Figure 3 The structures of fullerene, carbon nanotube, and graphene. ${ }^{[47]}$

Fullerene $\left(\mathrm{C}_{60}\right)$ has received great interests by researchers due to its unique electronic and structural properties. $\mathrm{C}_{60}$ contains a conjugated $p$ orbital system, which is beneficial for electron transfer in the photocatalytic process. Moreover, $\mathrm{C}_{60}$ has superior electron conductivity, which also contributes to photon-energy conversion. ${ }^{[51-53]}$ Compared with pure $\mathrm{ZnO}, \mathrm{ZnO}^{-} \mathrm{C}_{60}$ composites not only extend the absorbance in the visible light region, but also increase the absorption intensity of ${\mathrm{ZnO}-\mathrm{C}_{60}}_{0}$ composites with increase of $\mathrm{C}_{60}$ loading amounts, particularly, from $0.5 \%$ to $1.5 \%$ (Figure $4 \mathrm{~A}$ ). The light absorbance of $\mathrm{ZnO}^{-\mathrm{C}_{60}}$ composites at the wavelength of $600 \mathrm{~nm}$ changes with the mass ratio of $\mathrm{ZnO}^{-\mathrm{C}_{60}}$ composites (the inset of Figure $4 \mathrm{~A}){ }^{[54]}$ Compared with pure $\mathrm{ZnO}, \mathrm{ZnO}-\mathrm{C}_{60}$ composites possess a higher photocatalytic activity for degradation of methylene blue (MB) (Figure 4B). ${ }^{[54]}$ The most optimum condition appears at the $\mathrm{C}_{60}$ loading amount $1.5 \%$ with the rate constant $0.0569 \mathrm{~min}^{-1}$, which is 3 times higher than that of pure $\mathrm{ZnO}\left(0.0188 \mathrm{~min}^{-1}\right)$. The enhanced photocatalytic activity of $\mathrm{ZnO}^{-\mathrm{C}_{60}}$ composite is due to the high migration efficiency of photoexcited charge carriers across the interface of $\mathrm{C}_{60}$ and $\mathrm{ZnO}$. The high migration efficiency is attributed to the strong interaction between $\mathrm{ZnO}$ and $\mathrm{C}_{60}$ for the conjugative $p$ orbital system of $\mathrm{C}_{60}$. Furthermore, $\mathrm{C}_{60}$ can be easily adsorbed on the $\mathrm{ZnO}$ surface, which will protect the oxygen vacancies on the $\mathrm{ZnO}$ surface from the $\mathrm{ZnO}$ corrosion by $\mathrm{O}_{2}$ in solution. Therefore, $\mathrm{C}_{60}$ adsorption will inhibit $\mathrm{ZnO}$ photocorrosion and step up the photostability of $\mathrm{ZnO}$.
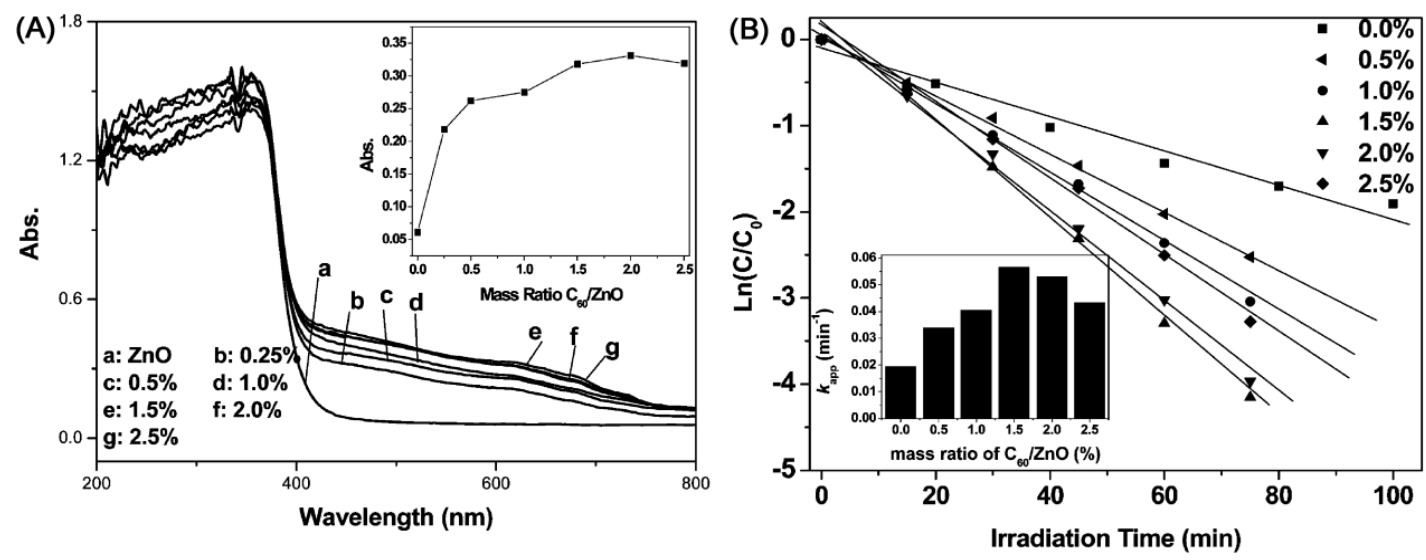

Figure 4 (A) DRS of $\mathrm{ZnO}$ hybridized by $\mathrm{C}_{60}$ with the different ration of $\mathrm{ZnO}$ and $\mathrm{C}_{60}$. (B) The photocatalytic degradation of $\mathrm{MB}$ over $\mathrm{ZnO}-\mathrm{C}_{60}$ composites under $\mathrm{UV}$-light illumination $(\lambda=254 \mathrm{~nm})$; Inset: effect of $\mathrm{C}_{60}$ loading on the apparent rate constant $(k){ }^{[54]}$ 
Carbon nanotube (CNT), with one-dimensional (1D) structure, is a potential candidate for anchoring semiconductor particles to construct high efficient CNT-based photocatalysts. ${ }^{[55-59]}$ Previous works have confirmed that combining $\mathrm{CNT}$ with $\mathrm{ZnO}$ is an efficient way to enhance photocatalytic performance. ${ }^{[60-63]}$ Because of the flexible $s p^{2}$-hybridized conjugated bonding structure, the 1D CNT has roomy molecular orbital and ultrafast and long distance electron transport capability for storing and shuttling electrons. The special property will bust the recombination of photogenerated electron-hole pairs. ${ }^{[55,64]}$ Moreover, the improved photocatalytic performance of $\mathrm{ZnO}-\mathrm{CNT}$ results from improving dispersion of photocatalysts and increasing exposure of more active sites. ${ }^{[65]}$ Because adsorbed CNT can alter the band structure of $\mathrm{ZnO}, \mathrm{CNT}$ can also act as a photosensitizer to sensitize ZnO. For example, multi-walled CNT (MWCNT) modified $\mathrm{ZnO}$ exhibits visible light photoactivity for photodegradation of $\mathrm{MB}{ }^{[32]}$ Figure $5 \mathrm{~A}$ shows that the MB degradation rate constant is $0.00387 \mathrm{~mol} \mathrm{~min}^{-1}$ for ZnO-MWCNT composites under visible light irradiation, whereas the photodegradation of MB is not observed for pure $\mathrm{ZnO}$ at the same condition. This photocatalysis result is consistent with the UV-DRS results (Figure 5B), and the MWCNT modification expands the visible light response of $\mathrm{ZnO}$. Under UV-irradiation (Figure 5C), the rate constant of ZnO-MWCNT composites is much higher $\left(0.01445 \mathrm{~min}^{-1}\right)$ than that of pure $\mathrm{ZnO}$ $\left(0.00286 \mathrm{~min}^{-1}\right)$. Figure $5 \mathrm{D}$ shows the proposed photocatalytic mechanism. ${ }^{[66]}$ Under visible light irriadiation, MWCNT absorbs visible irradiation and transfers the photogenerated electron into the conduction band of $\mathrm{ZnO}$. The organic dye was degraded on the $\mathrm{ZnO}$ surface, and the positively charged CNTs removed an electron from the valence band of $\mathrm{ZnO}$ and left a hole. Under UV light irradiation in the ZnO-MWCNT composites, the photogenerated electrons from $\mathrm{ZnO}$ move toward MWCNT and leave holes remain in $\mathrm{ZnO}$ valance band. The possibility of $\mathrm{e}^{-}-\mathrm{h}^{+}$pair recombination is reduced, and the photocatalytic activity of MB degradation is enhanced under UV light.

Graphene (GR) sheets, with two-dimensional (2D) structures, are used as coupling materials to anchor semiconductors for constructing effective photocatalysts with high solar energy conversion. ${ }^{[67,78]}$ Due to excellent properties of GR, wide range of researches have been performed to hybridize GR with $\mathrm{ZnO}$ to enhance its photocatalytic performance. ${ }^{[79-81]}$ Figure $6 \mathrm{~A}$ shows photocatalytic degradation of MB over GR, blank $\mathrm{ZnO}$, mechanical mixture of $\mathrm{ZnO} / \mathrm{GR}$ and $\mathrm{ZnO}-\mathrm{GR}$ composite (graphene $2.0 \mathrm{wt} \%$ ) under UV light irradiation, which demonstrates that $\mathrm{ZnO}-\mathrm{GR}$ composites have the highest photocatalytic activity. ${ }^{[45]}$ From Figure $6 \mathrm{~B}$, it can be seen that graphene sheets are not perfectly flat but have some wrinkles. The tight adsorption between $\mathrm{ZnO}$ and graphene makes electronic interaction possible and improves separation efficiency of photo-induced electrons and holes, which is verified by photocurrent measurement. Figure $6 \mathrm{C}$ indicates that the photocurrent of graphene hybridized $\mathrm{ZnO}$ is about 3.5 times higher than that of pure $\mathrm{ZnO}$. The enhanced photocatalytic activity of $\mathrm{ZnO}-\mathrm{GR}$ composite is due to the coupling of GR and $\mathrm{ZnO}$, which can promote photon-generated carrier separation and increase life time of photo-induced $\mathrm{e}^{-}-\mathrm{h}^{+}$pairs, or suppress charge carrier recombination (Figure 6D). Additionally, the presence of GR in the $\mathrm{ZnO}$-GR composite could enhance adsorption affinity toward $\mathrm{MB}$, which also contributes to improvement of photocatalytic activity of $\mathrm{ZnO}-\mathrm{GR}$ composite. ${ }^{[82-85]}$ Consequently, the improvement of photocatalytic activity of $\mathrm{ZnO}-\mathrm{GR}$ composites is also attributed to other factors such as rising the amount of electron acceptor and transport channel, increasing specific surface area of reactive sites, increasing light harvesting, and so on. ${ }^{[73,75,86-88]}$
(A)

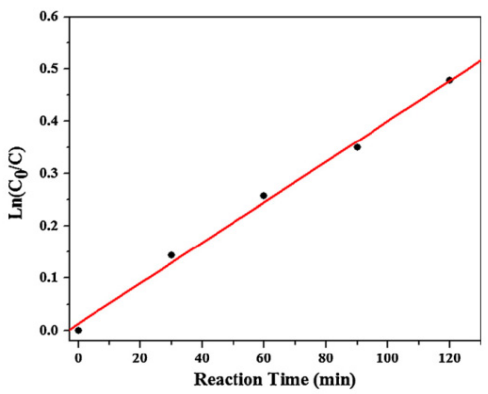

(C)

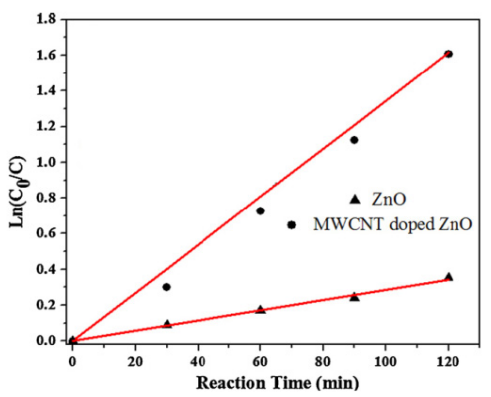

(B)

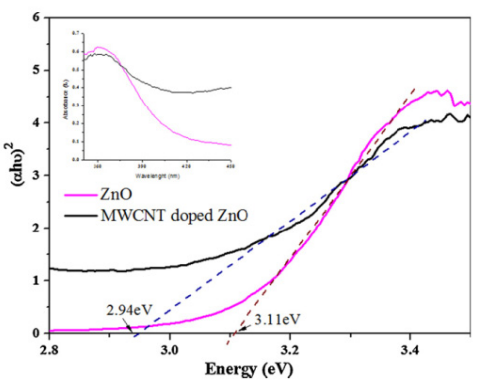

(D)
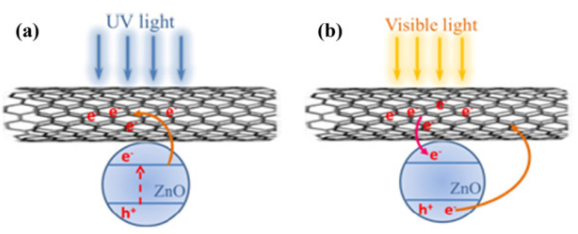

Figure 5 (A) Variation of $\operatorname{Ln}\left(C_{0} / C\right)$ vs. photo-irradiation time for photodegradation of MB under visible light on ZnO-MWCNT composites. (B) Plot of variation of $(\alpha \mathrm{h} v)^{2} v s$. energy (eV) for pure and ZnO-MWCNT composites (Inset: UV-vis spectra of pure ZnO and ZnO-MWCNT composites). (C) Variation of $\mathrm{Ln}\left(C_{0} / C\right)$ vs. photo-irradiation time under UV light on the pure $\mathrm{ZnO}$ and ZnO-MWCNT composites. (D) MWCNT inhibition of $\mathrm{e}^{-}-\mathrm{h}^{+}$recombination mechanism in the ZnO-MWCNT composites under UV light (a), and photosensitized mechanism (under visible light) of MWCNT in the ZnO-MWCNT composites (b). ${ }^{[6]}$ 


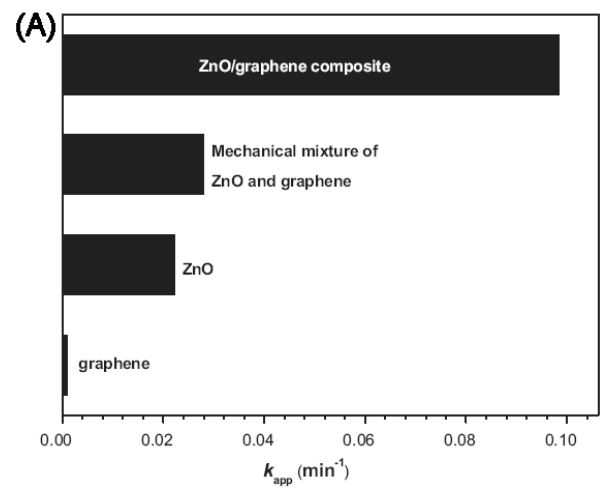

(B)
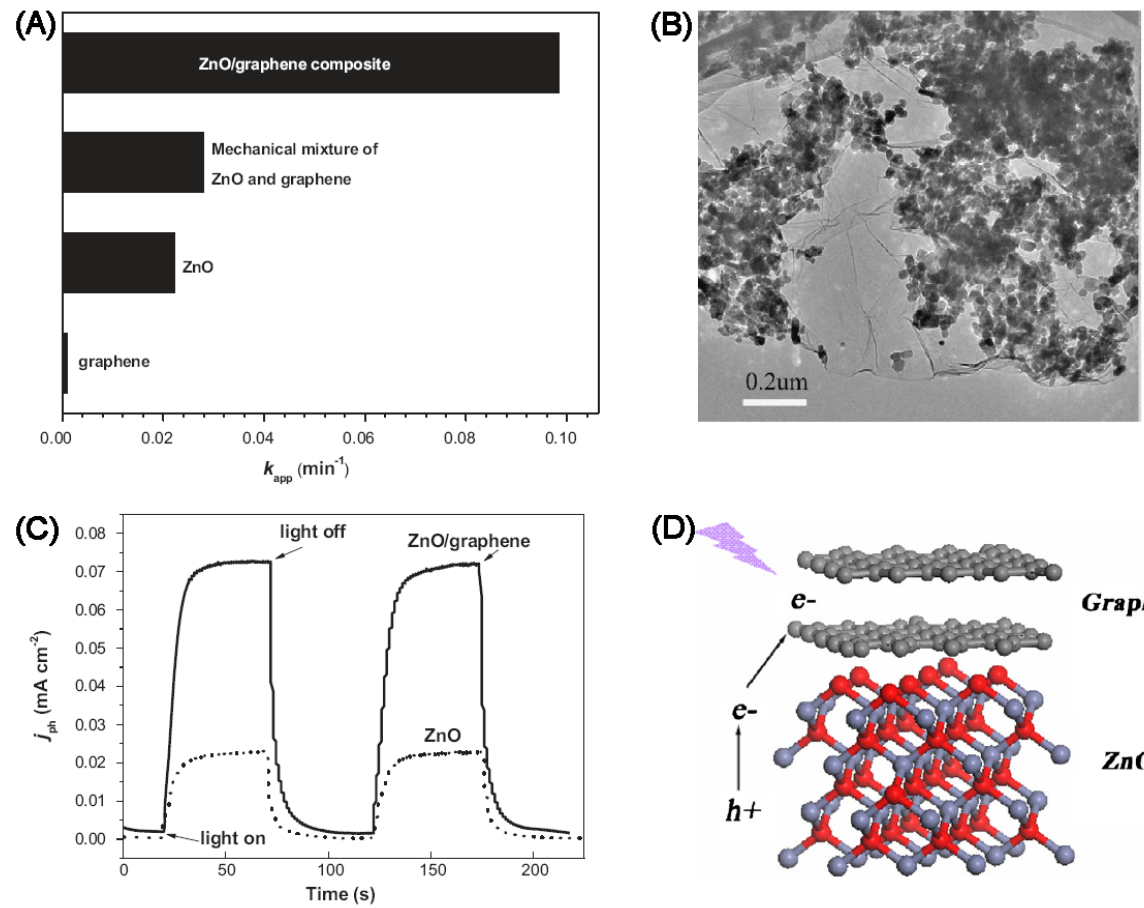

(D)

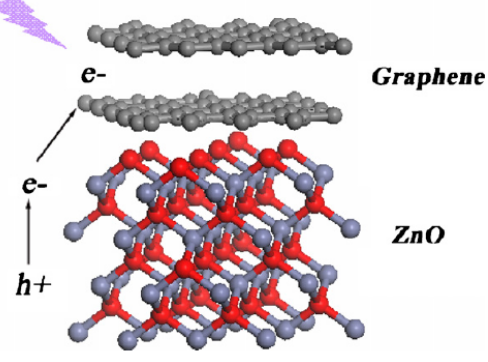

Figure 6 (A) The rate constant of MB photodegradation under UV light on graphene, $\mathrm{ZnO}$, mechanical mixture of $\mathrm{ZnO}$ and graphene (2.0 wt\%), and the ZnO-GR (graphene $2.0 \mathrm{wt} \%$ ) composite. (B) TEM images of ZnO-GR composite (2.0 wt\%). (C) Photocurrent transient responses of ZnO and $\mathrm{ZnO}-\mathrm{GR}$ electrodes. (D) Charge transfer mechanism of ZnO-GR composite under UV light irradiation. ${ }^{[45]}$

\section{Conclusions and outlook}

$\mathrm{ZnO}$-based carbon composites are promising photocatalysts to photodegrade organic pollutants. Carbon materials including $\mathrm{C}_{60}$, carbon tube, and graphene for improving photocatalytic performance of $\mathrm{ZnO}$ are comprehensively overviewed. A systematical understanding of the effects of carbon materials on enhancing the performance of $\mathrm{ZnO}$ photocatalysts for photodegradation of organic pollutants is summarized, for example, how to enhance structure stabilities, increase active adsorption sites, rise amounts of electron acceptor and transport channel, improve photosensitization, narrow the band gap, and so on. The basic mechanism behind the effects is discussed according to electron interaction between $\mathrm{ZnO}$ and carbon materials. Compared with CNTs, GR has some advantages in photocatalysis. Firstly, the theoretical specific surface area of GR is much higher than that of CNTs, resulting in more adsorption centers and active centers on the surface of GR. Secondly, the 2D structure of GR can assure better dispersion of $\mathrm{ZnO}$ nanoparticles on its surface in comparison with 1D CNTs. Thirdly, electrical conductivity and electron mobility of GR are much higher than that of CNTs due to flatter extended $\pi$-aromatic structure of GR, which is beneficial for electron capture and migration during photocatalytic process. Compared with CNTs and GR, $\mathrm{C}_{60}$ is excellent electron acceptors and electron donors, which enrich functionality of carbon materials in photocatalysis. Despite great accomplishment has demonstrated extraordinary potential of $\mathrm{ZnO}$-based carbon composites in the field of photocatalytic degradation of organic pollutants, big challenges is still remained. It is expected that further progress in understanding properties and applications of carbon modified $\mathrm{ZnO}$ nanomaterials will be accelerated in coming years.

\section{Acknowledgement}

This work was supported by the Natural Science Foundation project of China (Nos. 51602207 and 51501118), the Liaoning Province
Doctor Startup Fund (No. 201601149), the General Scientific Research Project of Education Office of Liaoning Province (No. L2015498), and the project funded by China Postdoctoral Science Foundation (No. 2016M590723).

\section{References}

[1] Gogate, P. R.; Pandit, A. B. Adv. Environ. Res. 2004, 8, 501.

[2] Low, J.; Yu, J.; Ho, W. J. Phys. Chem. Lett. 2015, 6, 4244.

[3] Wang, Y.; Li, T.; Bai, S.; Qi, K.; Cao, Z.; Zhang, K.; Wu, S.; Wang, D. Int. J. Hydrog. Energy 2016, 41, 276.

[4] Liu, M.; Xu, J.; Cheng, B.; Ho, W.; Yu, J. Appl. Surf. Sci. 2015, 332, 121.

[5] Dong, F.; Wu, L.; Sun, Y.; Fu, M.; Wu, Z.; Lee, S. C. J. Mater. Chem. 2011, 21, 15171.

[6] Marttinen, S. K.; Kettunen, R. H.; Sormunen, K. M.; Soimasuo, R. M.; Rintala, J. A. Chemosphere 2002, 46, 851.

[7] Fujishima, A.; Honda, K. Nature 1971, 238, 37.

[8] Liu, T.; Li, Y.; Zhang, H.; Wang, M.; Fei, X.; Duo, S.; Chen, Y.; Pan, J.; Wang, W. Appl. Surf. Sci. 2015, 357, 516.

[9] Wu, C. Appl. Surf. Sci. 2014, 319, 237.

[10] Sapkal, R. T.; Shinde, S. S.; Mahadik, M. A.; Mohite, V. S.; Waghmode, T. R.; Govindwar, S. P.; Rajpure, K. Y.; Bhosale, C. H. Journal of Photochemistry and Photobiology B: Biology 2012, 114, 102.

[11] Qi, K.; Zasada, F.; Piskorz, W.; Indyka, P.; Gryboś, J.; Trochowski, M.; Buchalska, M.; Kobielusz, M.; Macyk, W.; Sojka, Z. J. Phys. Chem. C 2016, 120, 5442 .

[12] Schneider, J.; Matsuoka, M.; Takeuchi, M.; Zhang, J.; Horiuchi, Y.; Anpo, M.; Bahnemann, D. W. Chem. Rev. 2014, 114, 9919.

[13] Yu, J.; Yu, Y.; Zhou, P.; Xiao, W.; Cheng, B. Appl. Catal. B: Environ. 2014, 156-157, 184.

[14] Hong, Y.; Zhang, J.; Huang, F.; Zhang, J.; Wang, X.; Wu, Z.; Lin, Z.; Yu, J. J. Mater. Chem. A 2015, 3, 13913.

[15] Baran, T.; Wojtyła, S.; Dibenedetto, A.; Aresta, M.; Macyk, W. Appl. Catal. B: Environ. 2015, 178, 170.

[16] Plaza, M.; Huang, X.; Ko, J. Y. P.; Shen, M.; Simpson, B. H.; 
Rodríguez-López, J.; Ritzert, N. L.; Letchworth-Weaver, K.; Gunceler, D.; Schlom, D. G.; Arias, T. A.; Brock, J. D.; Abruña, H. D. J. Am. Chem. Soc. 2016, 138, 7816 .

[17] Bi, C.; Cao, J.; Lin, H.; Wang, Y.; Chen, S. Mater. Lett. 2016, 166, 267.

[18] Chen, X.; Zhai, Y.; Li, J.; Fang, X.; Fang, F.; Chu, X.; Wei, Z.; Wang, X. Appl. Surf. Sci. 2014, 319, 216.

[19] Anas, S.; Rahul, S.; Babitha, K. B.; Mangalaraja, R. V.; Ananthakumar, S. Appl. Surf. Sci. 2015, 355, 98.

[20] Jing, W.; Qi, H.; Shi, J.; Jiang, Z.; Zhou, F.; Cheng, Y.; Gao, K. Appl. Surf. Sci. 2015, 355, 403.

[21] Lee, K. M.; Lai, C. W.; Ngai, K. S.; Juan, J. C. Water Res. 2016, 88, 428.

[22] Cheng, J.; Zhang, H.; Zhu, J.; Qian, L.; Lu, Q.; Wu, G.; Xu, J.; Zhu, J. Gen. Chem. 2016, 2, 31.

[23] Wang, Z. Mater. Today 2004, 7, 26.

[24] Kandavelu, V.; Kastien, H.; Thampi, K. R. Appl. Catal. B: Environ. 2004, $48,101$.

[25] Calzolari, A.; Ruini, A.; Catellani, A. J. Am. Chem. Soc. 2011, 133, 5893.

[26] Liu, X.; Huang, W.; Cheng, H.; Huang, B.; Bai, D.; Fu, F.; Wu, H.; Li, L. Appl. Surf. Sci. 2015, 356, 240.

[27] Zhang, P.; Li, B.; Zhao, Z.; Yu, C.; Hu, C.; Wu, S.; Qiu, J. ACS Appl. Mater. Interfaces 2014, 6, 8560 .

[28] Tripathy, N.; Ahmad, R.; Kuk, H.; Lee, D. H.; Hahn, Y.-B.; Khang, G. J. Photochem. Photobiol. B-Biol. 2016, 161, 312.

[29] Yu, J.; Li, C.; Liu, S. J. Colloid Interface Sci. 2008, 326, 433.

[30] Ma, Q. L.; Xiong, R.; Zhai, B.-g.; Huang, Y. M. Appl. Surf. Sci. 2015, 324,842

[31] Rehman, S.; Ullah, R.; Butt, A. M.; Gohar, N. D. J. Hazard. Mater. 2009, 170,560

[32] Yang, S.; Wang, J.; Li, X.; Zhai, H.; Han, D.; Wei, B.; Wang, D.; Yang, J. Appl. Surf. Sci. 2014, 319, 211.

[33] Son, D. I.; Kwon, B. W.; Yang, J. D.; Park, D. H.; Angadi, B.; Choi, W. K. J. Mater. Chem. 2012, 22, 816.

[34] Shi, R.; Yang, P.; Song, X.; Wang, J.; Che, Q.; Zhang, A. Appl. Surf. Sci. 2016, 366, 506.

[35] Guo, Y.; Lin, S.; Li, X.; Liu, Y. Appl. Surf. Sci. 2016, 384, 83.

[36] Sudheer Khan, S. J. Photochem. Photobiol. B-Biol. 2015, 142, 1.

[37] Yu, J.; Ma, T.; Liu, G.; Cheng, B. Dalton Trans. 2011, 40, 6635.

[38] Ameen, S.; Shaheer Akhtar, M.; Seo, H.-K.; Shik Shin, H. Mater. Lett. 2013, 100, 261

[39] Zhou, X.; Shi, T.; Zhou, H. Appl. Surf. Sci. 2012, 258, 6204.

[40] Wang, J.; Tsuzuki, T.; Tang, B.; Hou, X.; Sun, L.; Wang, X. ACS Appl. Mater. Interfaces 2012, 4, 3084.

[41] Fan, H.; Zhao, X.; Yang, J.; Shan, X.; Yang, L.; Zhang, Y.; Li, X.; Gao, M. Catal. Commun. 2012, 29, 29.

[42] Gupta, S. M.; Tripathi, M. Chin. Sci. Bull. 2011, 56, 1639.

[43] Kadam, A.; Dhabbe, R.; Gophane, A.; Sathe, T.; Garadkar, K. J. Photochem. Photobiol. B- Biol. 2016, 154, 24.

[44] Tripathi, R. M.; Bhadwal, A. S.; Gupta, R. K.; Singh, P.; Shrivastav, A.; Shrivastav, B. R. J. Photochem. Photobiol. B-Biol. 2014, 141, 288.

[45] Xu, T.; Zhang, L.; Cheng, H.; Zhu, Y. Appl. Catal. B: Environ. 2011, 101, 382.

[46] Bai, X.; Wang, L.; Zhu, Y. ACS Catal. 2012, 2, 2769.

[47] Cao, S.; Yu, J. J. Photochem. Photobiol. C: Photochem. Rev. 2016, 27, 72.

[48] Yang, M.-Q.; Weng, B.; Xu, Y.-J. J. Mater. Chem. A 2014, 2, 1710.

[49] Yang, M.-Q.; Weng, B.; Xu, Y.-J. Langmuir 2013, 29, 10549.

[50] Liu, S.; Chen, Z.; Zhang, N.; Tang, Z.-R.; Xu, Y.-J. J. Phys. Chem. C
2013, 117,8251

[51] Qi, K.; Selvaraj, R.; Al Fahdi, T.; Al-Kindy, S.; Kim, Y.; Wang, G.-C.; Tai, C.-W.; Sillanpää, M. Appl. Surf. Sci. 2016, 387, 750.

[52] Guldi, D. M. Chem. Commun. 2000, 321.

[53] Jens Cremer, P. B., Martijn M. Wienk, Rene A. J. Janssen Chem. Mater. 2006, 18,5832 .

[54] Fu, H.; Xu, T.; Zhu, S.; Zhu, Y. Environ. Sci. Technol. 2008, 42, 8064.

[55] Kauffman, D. R.; Star, A. Angew. Chem., Int. Ed. 2008, 47, 6550.

[56] Gooding, J. J. Electrochimi. Acta 2005, 50, 3049.

[57] Tada, K.; Furuya, S.; Watanabe, K. Phys. Rev. B 2001, 63.

[58] Hasobe, T.; Fukuzumi, S.; Kamat, P. V. Angew. Chem. 2006, 118, 769.

[59] Hu, Y. H.; Ruckenstein, E. Chem. Phys. Lett. 2006, 425, 306.

[60] Saleh, T. A.; Gondal, M. A.; Drmosh, Q. A.; Yamani, Z. H.; Al-yamani, A. Chem. Eng. J. 2011, 166, 407.

[61] Mohamed, R. M.; Abdel Salam, M. Mater. Res. Bull. 2014, 50, 85.

[62] Liu, P.; Guo, Y.; Xu, Q.; Wang, F.; Li, Y.; Shao, K. Ceram. Int. 2014, 40, 5629.

[63] Dai, K.; Dawson, G.; Yang, S.; Chen, Z.; Lu, L. Chem. Eng. J. 2012, 191, 571.

[64] Weng, B.; Liu, S.; Zhang, N.; Tang, Z.-R.; Xu, Y.-J. J. Catal. 2014, 309, 146.

[65] Ahmad, M.; Ahmed, E.; Hong, Z. L.; Jiao, X. L.; Abbas, T.; Khalid, N. R. Appl. Surf. Sci. 2013, 285, 702.

[66] Samadi, M.; Shivaee, H. A.; Zanetti, M.; Pourjavadi, A.; Moshfegh, A. J Mol. Catal. A: Chem. 2012, 359, 42.

[67] Zhang, N.; Zhang, Y.; Xu, Y.-J. Nanoscale 2012, 4, 5792.

[68] Xiang, Q.; Yu, J.; Jaroniec, M. Chem. Soc. Rev. 2012, 41, 782.

[69] Liu, H.; Hu, Y.; Zhang, Z.; Liu, X.; Jia, H.; Xu, B. Appl. Surf. Sci. 2015, $355,644$.

[70] Low, J.; Yu, J.; Li, Q.; Cheng, B. Phys. Chem. Chem. Phys. 2014, 16, 1111.

[71] Wu, D.; An, T.; Li, G.; Wang, W.; Cai, Y.; Yip, H. Y.; Zhao, H.; Wong, P. K. Appl. Surf. Sci. 2015, 358, 137.

[72] Atchudan, R.; Edison, T. N. J. I.; Perumal, S.; Karthikeyan, D.; Lee, Y. R. J. Photochem. Photobiol. B-Biol. 2016, 162, 500.

[73] Pawar, R. C.; Lee, C. S. Appl. Catal. B: Environ. 2014, 144, 57.

[74] Guo, R.; Wu, W. Gen. Chem. 2016, 2, 66.

[75] Sun, L.; Shao, R.; Tang, L.; Chen, Z. J. Alloy. Compd. 2013, 564, 55.

[76] Hayashi, H.; Lightcap, I. V.; Tsujimoto, M.; Takano, M.; Umeyama, T.; Kamat, P. V.; Imahori, H. J. Am. Chem. Soc. 2011, 133, 7684.

[77] Liu, X.; Pan, L.; Lv, T.; Sun, Z. J. Colloid Interface Sci. 2013, 394, 441.

[78] Guo, R.; Wu, W. Gen. Chem. 2016, 2, 89.

[79] Kang, W.; Jimeng, X.; Xitao, W. Appl. Surf. Sci. 2016, 360, 270.

[80] Chen, Z.; Zhang, N.; Xu, Y.-J. CrystEngComm 2013, 15, 3022.

[81] Song, N.; Fan, H.; Tian, H. Appl. Surf. Sci. 2015, 353, 580.

[82] Rokhsat, E.; Akhavan, O. Appl. Surf. Sci. 2016, 371, 590.

[83] Zhang, Q.; Tian, C.; Wu, A.; Tan, T.; Sun, L.; Wang, L.; Fu, H. J. Mater. Chem. 2012, 22, 11778.

[84] Weng, B.; Yang, M.-Q.; Zhang, N.; Xu, Y.-J. J. Mater. Chem. A 2014, 2, 9380.

[85] Peng, Y.; Ji, J.; Chen, D. Appl. Surf. Sci. 2015, 356, 762.

[86] Worajittiphon, P.; Pingmuang, K.; Inceesungvorn, B.; Wetchakun, N.; Phanichphant, S. Ceram. Int. 2015, 41, 1885.

[87] Yu, Z. B.; Xie, Y. P.; Liu, G.; Lu, G. Q.; Ma, X. L.; Cheng, H.-M. J. Mater. Chem. A 2013, 1, 2773.

[88] Sarkar, S.; Basak, D. CrystEngComm 2013, 15, 7606. 